\title{
Autophosphorylation of Yeast Hexokinase PII
}

\author{
By R. FERNÁNDEZ, P. HERRERO, E. FERNÁNDEZ, \\ T. FERNÁNDEZ, Y. S. LÓPEZ-BOADO AND F. MORENO* \\ Departamento de Biología Funcional, Area de Bioquimica y Biologia Molecular, Facultad de \\ Medicina, Universidad de Oviedo, 33071-Oviedo, Spain
}

(Received 3 March 1988; revised 15 May 1988)

\begin{abstract}
Autophosphorylation of hexokinase PII was studied using an enzyme purified from Saccharomyces cerevisiae. Incubation of this enzyme preparation with $[\gamma-32 \mathrm{P}] \mathrm{ATP}$ and $\mathrm{Mn}^{2+}$ or $\mathrm{Mg}^{2+}$ gave a phosphoprotein of molecular mass 58000 which corresponded to hexokinase PII. D-Xylose stimulated autophosphorylation of hexokinase PII. Dilution of hexokinase PII over a 10-fold concentration range did not change the specific activity of hexokinase PII autophosphorylation suggesting that it may occur by an intramolecular mechanism.
\end{abstract}

\section{INTRODUCTION}

Three glucose-phosphorylating enzymes, glucokinase and two hexokinase isoenzymes PI and PII have been described in yeast (Colowick, 1973; Barnard, 1975). In the last few years, special attention has been given to hexokinase PII, since it has both catalytic and regulatory properties (Frohlich et al., 1984; Entian et al., 1984; Fernández et al., 1984). In particular, the carbon catabolic repression of invertase and maltase was relieved in yeast with xylose-inactivated hexokinase PII (Fernández et al., 1984) and by a mutation in the hexokinase PII structural gene (Entian \& Mecke, 1982). These results suggested a direct role of hexokinase PII in the regulation of carbon catabolite repression in yeast.

The detailed molecular mechanism of catabolite repression is unknown, but inactivation of yeast hexokinase PII by xylose is not paralleled by the loss of hexokinase PII protein (Fernández et al., 1987). However, it has been suggested that xylose-induced phosphorylation of hexokinase PII in vivo may produce a change in enzyme conformation which could provide the triggering signal to activate an additional activity (Fernández et al., 1987). We therefore examined autophosphorylation of hexokinase PII as a possible triggering signal to activate the carbon catabolite derepression process. Here we report the autophosphorylation of hexokinase PII and we characterize the mechanism and kinetics of this reaction.

\section{METHODS}

Materials. Yeast extract was obtained from Difco. Hydroxyapatite HA-Ultrogel was purchased from LKB. Chromatofocusing gel PBE94 was obtained from Pharmacia. Material for electrophoresis was from Bio-Rad Laboratories. $\left[\gamma^{-32}\right.$ P]ATP $\left(3000 \mathrm{Ci} \mathrm{mmol}^{-1} ; 111 \mathrm{TBq} \mathrm{mmol}^{-1}\right)$ was from New England Nuclear. Sigma reagents and enzymes were used throughout.

Strain and growth conditions. Saccharomyces cerevisiae mutant strain D.308.3 (MAT $\alpha$ hxk1 hxk2 glkl adel trpl his 2 met 14), obtained from the Yeast Genetic Stock Center, (University of California, Berkeley, USA), was used as recipient in transformation experiments. Plasmid YRp/HXK 2-5 was kindly provided by K. D. Entian (University of Tübingen, FRG) (Entian et al., 1985) and vector Yep1357 was used as a multicopy vector (Rodicio \& Zimmermann, 1985). Hybrid plasmids Yep1357-HXK 2-5, complementing the $h x k 2$ mutation, were selected in a medium with glucose as carbon source as described by Fernández et al. (1987). Due to the multicopy effect of the vector Yep1357 an approximate 20-fold increase in the specific activity of hexokinase PII was observed in the Yep1357-HXK 2-5 transformant of D.308.3 compared to the wild-type strain. The Yep1357-HXK 2-5 transformant of D.308.3 was used as one of the sources of hexokinase PII. 
The cells were grown in flasks with $300 \mathrm{ml}$ medium containing $1 \%(\mathrm{w} / \mathrm{v})$ yeast extract and $2 \%(\mathrm{w} / \mathrm{v})$ glucose, supplemented with $30 \mathrm{mg}$ adenine $\mathrm{l}^{-1}$, on a rotatory shaker at $28^{\circ} \mathrm{C}$. Growth was followed by determination of the optical density at $600 \mathrm{~nm}$. Yeast were harvested from cultures at an $\mathrm{OD}_{600}$ of 0.9 when the sugar concentration reached $50 \mathrm{mM}$ (repressed cells). The cells were washed twice with distilled water and resuspended in $10 \mathrm{~mm}$ potassium phosphate, $\mathrm{pH} 7 \cdot 0$ for further treatment.

Sources of hexokinase PII. Two different sources of hexokinase PII have been used with identical results: (a) hexokinase PII from the Yep1357-HXK 2-5 transformant of D.308.3 purified using a three-step procedure (cell-free extract preparation, chromatofocusing and hydroxyapatite chromatography as described by Fernández et al., 1986); (b) Sigma hexokinase PII (H-5875), which was further purified by chromatography on hydroxyapatite HA-Ultrogel (Moreno et al., 1986).

The samples containing hexokinase PII $(20 \mu \mathrm{g})$ from the last purification step were analysed by SDS-PAGE. We concluded that the hexokinase PII had been purified to homogeneity, from both sources, as the last enzyme preparation had only a single protein band $(58 \mathrm{kDa})$ (Fernández et al., 1987).

Autophosphorylation assay. Hexokinase PII, dialysed against $10 \mathrm{~mm}$-potassium phosphate buffer, $\mathrm{pH} 7 \cdot 0$, was diluted 25 -fold with $50 \mathrm{mM}-\mathrm{HEPES} / \mathrm{NaOH}, \mathrm{pH} \mathrm{7.5}$, to give a final concentration of $172 \mu \mathrm{g}$ protein $\mathrm{ml}^{-1}$. Hexokinase PII $(0.5$ to $5 \mu \mathrm{g})$ was then incubated at $4{ }^{\circ} \mathrm{C}$ or $30^{\circ} \mathrm{C}$ in $50 \mu 150 \mathrm{mM}-\mathrm{HEPES} / \mathrm{NaOH}, \mathrm{pH} 7 \cdot 5$. $\mathrm{Mn}^{2+}$, $\mathrm{Mg}^{2+}$, D-xylose and $\left[\gamma^{32} \mathrm{P}\right]$ ATP $\left(1 \times 10^{7}\right.$ d.p.m. $)$ were added at the concentrations indicated in the Figure legends. The reaction was started by addition of the enzyme protein and the incubation was continued for various time periods.

The reaction was terminated by adding $15 \mu \mathrm{l}$ of 4 -fold concentrated Laemmli sample buffer to obtain final concentrations of the following components: $2 \%(w / v)$ SDS; $0.5 \%(w / v) \beta$-mercaptoethanol; $0.01 \%(w / v)$ bromphenol blue; $10 \%$ (v/v) glycerol; 2 mM-EDTA and $60 \mathrm{mM}-\mathrm{Tris} / \mathrm{HCl}, \mathrm{pH} 7.0$ (Britton et al., 1982). This mixture was heated immediately in a boiling water-bath for $3 \mathrm{~min}$. The proteins were separated by SDS-PAGE using $3.5 \%(\mathrm{w} / \mathrm{v})$ stacking and $12 \%(\mathrm{w} / \mathrm{v})$ resolving polyacrylamide gels according to the method of Britton et al. (1982). Proteins were fixed and stained for $15 \mathrm{~min}$ at $55^{\circ} \mathrm{C}$ with $45 \%(\mathrm{v} / \mathrm{v})$ methanol, $10 \%(\mathrm{v} / \mathrm{v})$ acetic acid containing $0 \cdot 25 \%(\mathrm{w} / \mathrm{v})$ Coomassie blue. The gels were destained at $55{ }^{\circ} \mathrm{C}$ for $5 \mathrm{~h}$ in $7.5 \%(\mathrm{v} / \mathrm{v})$ acetic acid, $5 \%(\mathrm{v} / \mathrm{v})$ methanol and dried in vacuo for $2 \mathrm{~h}$ at $45^{\circ} \mathrm{C}$.

Radioactivity was located in gel fragments by autoradiography and quantified by measuring the area of the peak obtained by scanning for absorbance at $560 \mathrm{~nm}$ with a Joyce Loebl scanner.

\section{RESULTS}

\section{Effect of D-xylose, $\mathrm{Mg}^{2+}$ and $\mathrm{Mn}^{2+}$ on hexokinase PII autophosphorylation}

An autoradiogram showing the in vitro autophosphorylation at $4{ }^{\circ} \mathrm{C}$ of hexokinase PII, purified to homogeneity from the Yep1357-HXK 2-5 transformant of D.308.3, is shown in Fig. 1. The phosphoprotein had a molecular mass of $58 \mathrm{kDa}$. An identical molecular mass has been described for hexokinase PII protein (Fernández et al., 1987). In the absence of $\mathrm{Mn}^{2+}$ autophosphorylation occurred slowly and was not detected using $\mathrm{Mg}^{2+}$ under these experimental conditions. Xylose $(100 \mathrm{mM})$ stimulated the incorporation of ${ }^{32} \mathbf{P}$ from $\left[\gamma^{32} \mathrm{P}\right] A T P$ into hexokinase PII. Within $1 \mathrm{~min}$, autophosphorylation of hexokinase PII, in the absence of xylose in the reaction mixture, reached $40 \%$ of the autophosphorylation value reached in the presence of the pentose.

\section{Time-course of hexokinase PII autophosphorylation}

Fig. 2 shows the time-course of in vitro autophosphorylation of hexokinase PII at $4{ }^{\circ} \mathrm{C}$ using $4 \mu \mathrm{M}-\mathrm{ATP}$ and $\mathrm{Mn}^{2+}$ (Fig. 2A) and at $30^{\circ} \mathrm{C}$ using $4 \mathrm{mM}-\mathrm{ATP}$ and $\mathrm{Mg}^{2+}$ (Fig. 2B). D-Xylose stimulated the incorporation of ${ }^{32} \mathrm{P}$ from $\left[\gamma-{ }^{32} \mathrm{P}\right] \mathrm{ATP}$ into hexokinase PII under both sets of experimental conditions described. As shown in Fig. 2A, within $50 \mathrm{~s}$ autophosphorylation of hexokinase PII reached $50 \%$ of the maximum. Maximal phosphorylation was reached after about $2 \mathrm{~min}$. Incubations for longer periods produced a decrease in ${ }^{32} \mathrm{P}$ incorporation into hexokinase PII. Fig. 2B shows the time-course of autophosphorylation of hexokinase PII at $30{ }^{\circ} \mathrm{C}$. Within $5 \mathrm{~min}$, autophosphorylation of hexokinase PII reached $50 \%$ of the maximum and a steady-state value was reached after about $20 \mathrm{~min}$.

\section{Effect of hexokinase PII concentration on autophosphorylation}

Because the mechanism of hexokinase PII autophosphorylation could take place either by an intramolecular or by an intermolecular process, the influence of enzyme concentration on the 
(a) (b) (c) $\quad$ (d)

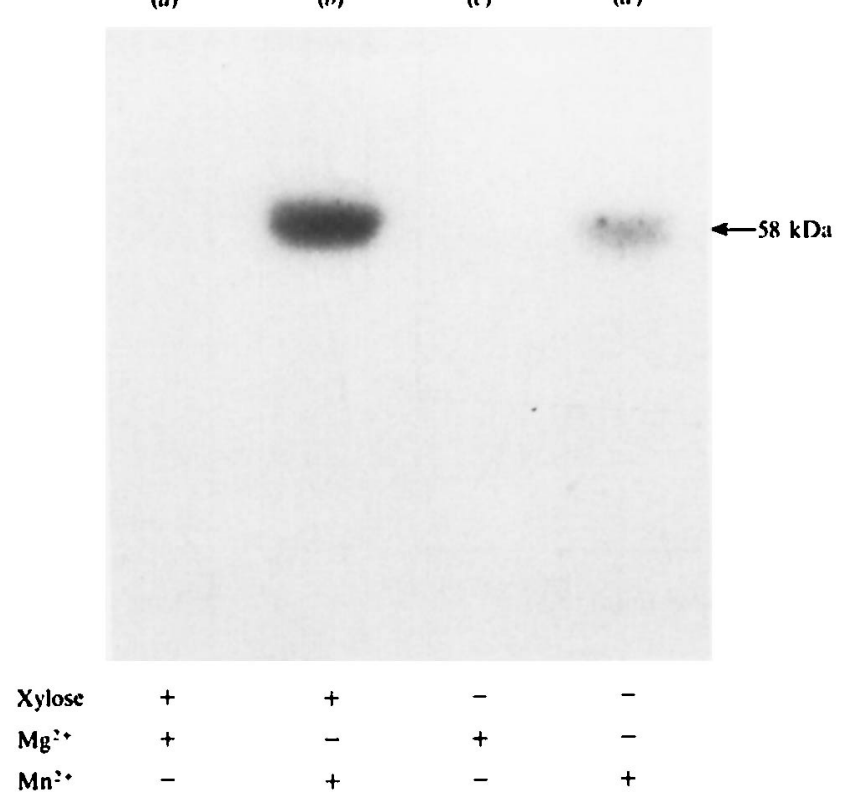

Fig. 1. Effect of D-xylose, $\mathrm{Mg}^{2+}$ and $\mathrm{Mn}^{2+}$ on the autophosphorylation of hexokinase PII. Purified hexokinase PII $(5 \mu \mathrm{g})$, obtained from the Yep1357-HXK 2-5 transformant of D.308.3, was used to assay autophosphorylation. After $1 \mathrm{~min}$ incubation at $4{ }^{\circ} \mathrm{C}$ samples were taken for the measurement of ${ }^{32} \mathrm{P}$ incorporation into protein. The first reaction mixture contained $50 \mathrm{~mm}-\mathrm{HEPES} / \mathrm{NaOH}, \mathrm{pH} 7 \cdot 5,4 \mu \mathrm{M}-\gamma-$ $\left.{ }^{32} \mathrm{P}\right] \mathrm{ATP}$ and $12 \mathrm{mM}-\mathrm{MnCl}_{2}$. Additional components were $100 \mathrm{mM}$-D-xylose (lane $b$ ) or $50 \mathrm{~mm}$ HEPES/ $\mathrm{NaOH}, \mathrm{pH} \mathrm{7.5}$, in place of xylose (lane $d$ ). The second reaction mixture contained $12 \mathrm{mM}-$ $\mathrm{MgCl}_{2}$ in place of $\mathrm{MnCl}_{2}$. Additional components were $100 \mathrm{mM}$-D-xylose (lane $a$ ) or $50 \mathrm{~mm}$ HEPES/ $\mathrm{NaOH}, \mathrm{pH} 7 \cdot 5$, in place of xylose (lane $c$ ). The reactions were terminated by heating with SDSgel electrophoresis sample buffer for $3 \mathrm{~min}$. The proteins were separated by SDS-PAGE. Gels were dried and exposed to $\mathrm{X}$-ray films for autoradiography. Identical results were obtained by using the two different sources of hexokinase PII indicated in Methods.

reaction rate was investigated. In an intramolecular reaction, the velocity at a constant ATP concentration would be linear (first-order) with respect to enzyme concentration, and parabolic (second-order) in an intermolecular reaction (Huang et al., 1986). Furthermore, a plot of log velocity versus log enzyme concentration (a van't Hoff plot) would yield a slope equal to the enzyme stoichiometry in the reaction. Such a plot would have a slope of 1 for an intramolecular or a slope of 2 for an intermolecular reaction. The results obtained demonstrated that the specific activity of hexokinase PII autophosphorylation is independent of the protein concentration over a 10-fold dilution range (data not shown). Analysis of the relationship between reaction rate and protein concentration by means of a van't Hoff plot (Fig. 3) shows that the slope equals 1.0. These findings indicate that the autophosphorylation of hexokinase PII is intramolecular.

\section{DISCUSSION}

The results presented in this report demonstrate that hexokinase PII can undergo autophosphorylation. The rate of autophosphorylation and also the final extent of ${ }^{32} \mathrm{P}$ incorporation were stimulated by the presence of $\mathrm{D}$-xylose in the assay mixture.

Protein autophosphorylation is usually measured at $4{ }^{\circ} \mathrm{C}$ using $\mathrm{Mn}^{2+}$ and a low ATP concentration. Hexokinase PII autophosphorylation under these assay conditions was saturated within $2 \mathrm{~min}$ and then declined (Fig. 2A). The reversal of autophosphorylation was only observed at very low ATP concentrations. The kinetics were similar to those observed for the 

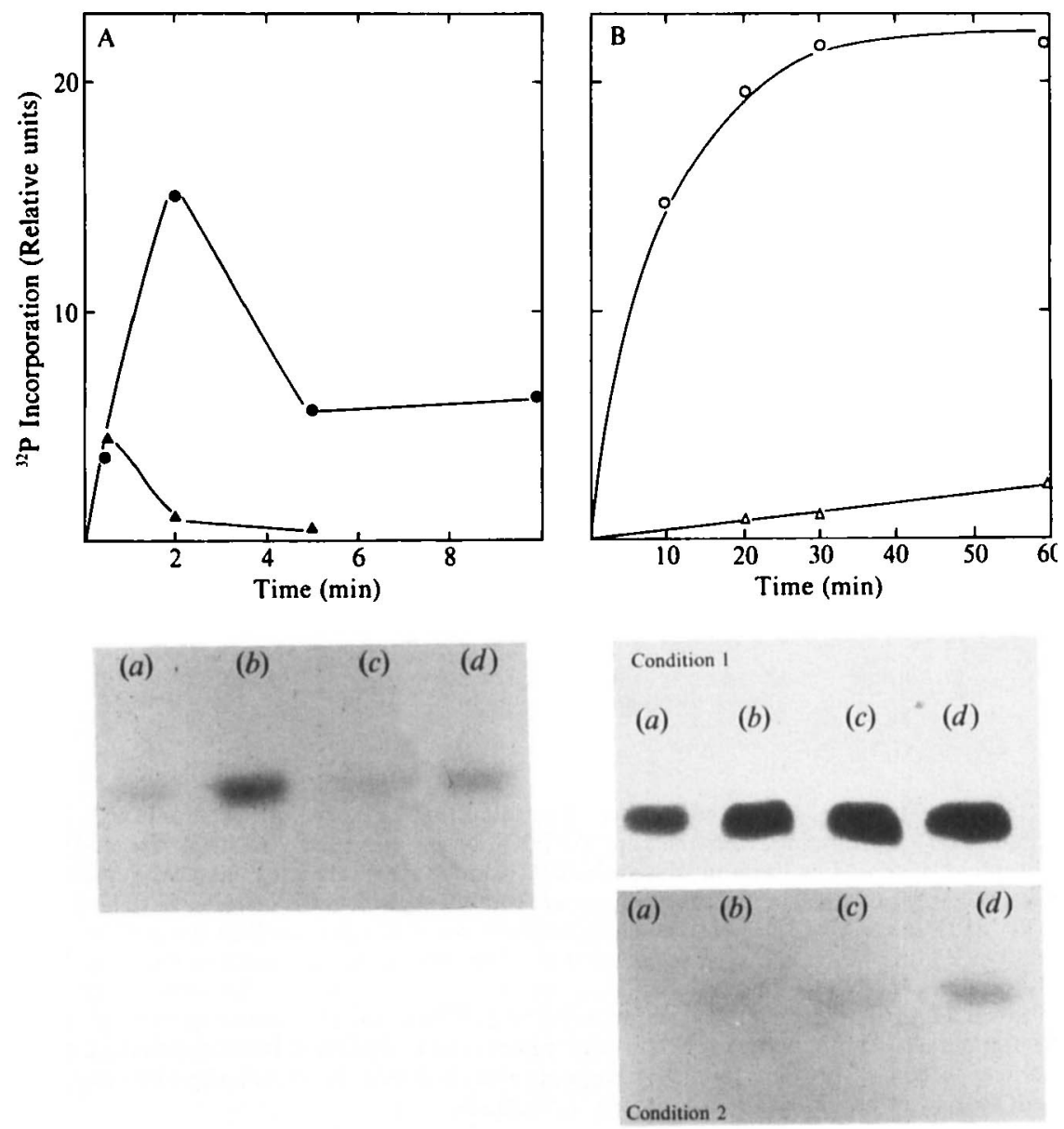

Fig. 2. Autophosphorylation of hexokinase PII under different assay conditions. A, Time-course of autophosphorylation under different assay conditions using $5 \mu \mathrm{g}$ hexokinase PII. At various times, samples were taken for the measurement of ${ }^{32} \mathrm{P}$ incorporation into protein. The basic reaction mixture contained $50 \mathrm{~mm}$-HEPES/NaOH, pH 7.5, $4 \mu \mathrm{M}-[\gamma-32 \mathrm{P}] \mathrm{ATP}$ and $12 \mathrm{mM}-\mathrm{MnCl}_{2}$. Additional components were (1) $100 \mathrm{mM}$-D-xylose (๑) or (2) $50 \mathrm{mM}$-HEPES/NaOH, pH 7.5, in place of xylose (A). Below A is an autoradiogram of hexokinase PII samples separated by SDS-PAGE after incubation at $4{ }^{\circ} \mathrm{C}$ for $30 \mathrm{~s}$ (lane $a$ ), $2 \mathrm{~min}$ (lane $b$ ), $5 \mathrm{~min}$ (lane $c$ ) or $10 \mathrm{~min}$ (lane $d$ ), under condition 1. B, Time-course of autophosphorylation under different assay conditions using $5 \mu \mathrm{g}$ hexokinase PII. At various times, samples were taken for the measurement of ${ }^{32} \mathrm{P}$ incorporation into protein. The basic reaction mixture contained $50 \mathrm{~mm}-\mathrm{HEPES} / \mathrm{NaOH}, \mathrm{pH} 7.5,4 \mathrm{~mm}-\left[\gamma^{-32} \mathrm{P}\right] \mathrm{ATP}$ and $12 \mathrm{mM}-\mathrm{MgCl}_{2}$. Additional components were (1) $100 \mathrm{mM}$-D-xylose (O) or (2) $50 \mathrm{mM}-\mathrm{HEPES} / \mathrm{NaOH}, \mathrm{pH} 7 \cdot 5$, in place of xylose $(\triangle)$. Below B are autoradiograms of hexokinase PII samples separated by SDS-PAGE after incubation at $30^{\circ} \mathrm{C}$ for $10 \mathrm{~min}$ (lane $a$ ), $20 \mathrm{~min}$ (lane $b$ ), $30 \mathrm{~min}$ (lane $c$ ) or $60 \mathrm{~min}$ (lane $d$ ) under condition 1 or condition 2. Identical results were obtained by using the two different sources of hexokinase PII indicated in Methods. The radioactivity located in gels by autoradiography was quantified by measuring the area of the peak obtained by scanning for absorbance at $560 \mathrm{~nm}$ and expressed as relative units.

reversal of autophosphorylation of type II cAMP-dependent protein kinase. This reversal is attributed to the increase of ADP concentration in the reaction mixture (Erlichman et al., 1983). Under the other assay conditions studied, protein phosphorylation slowly increased throughout a long incubation period reaching a steady state (Fig. 2B). These differential kinetics could be explained if hexokinase PII were a protein kinase presenting autophosphorylation (Blowers \& Trewavas, 1987). 


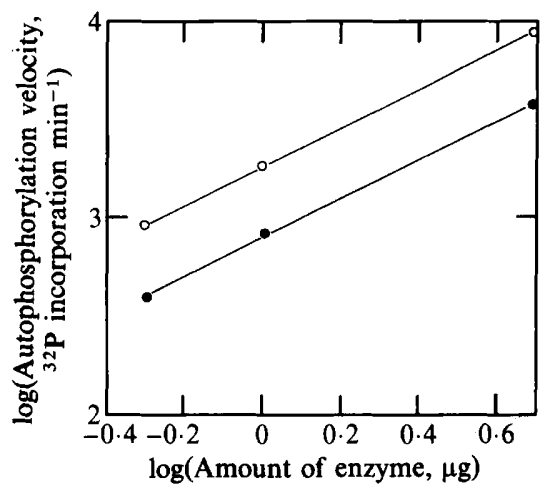

Fig. 3. Effect of enzyme concentration on autophosphorylation. Relationship between log hexokinase PII autophosphorylation velocity and log enzyme concentration (van't Hoff plot). The reaction rates were determined under the standard assay conditions of Fig. 2A containing $100 \mathrm{~mm}$-D-xylose and 0.5 to $5 \mu \mathrm{g}$ hexokinase PII (O) or were determined under the standard assay conditions of Fig. $2 \mathrm{~B}$ containing $100 \mathrm{mM}$-D-xylose and 0.5 to $5 \mu \mathrm{g}$ of hexokinase PII (O). The slope is 1.0 .

The mechanism of hexokinase PII autophosphorylation appears to be intramolecular since phosphorylation was first-order with respect to enzyme concentration. This approach was used previously to determine the mechanism of autophosphorylation of the type II cAMP-dependent protein kinase (Erlichman et al., 1983), the insulin receptor-kinase (Shia et al., 1983), $\mathrm{Ca}^{2+}$ calmodulin-dependent protein kinase (Lai et al., 1986), and protein kinase C (Huang et al., 1986). These studies have led to the conclusion that all of these kinases undergo intramolecular autophosphorylation.

The essential role of hexokinase PII for triggering glucose repression seems to be established (Frohlich et al., 1984; Entian et al., 1984; Fernández et al., 1984), but the molecular mechanism is still unknown. Work in this laboratory has established that inactivation of yeast hexokinase PII by xylose is not correlated with the loss of hexokinase PII protein. However, derepression of maltase and invertase synthesis takes place when xylose is present in the culture medium (Fernández et al., 1984). It was suggested that xylose-induced phosphorylation of hexokinase PII in vivo may produce a change in the enzyme conformation which could provide the triggering signal to activate an additional activity (Fernández et al., 1987). The present results suggest that hexokinase PII has a xylose-induced protein kinase activity which autophosphorylates the enzyme and could catalyse the phosphorylation of an inactive derepressing signal to an active one.

We thank Professor S. Gascón for his interest in this work and Dr Ma. J. Mazón for the many interesting suggestions. This work was supported by grants from the CAICYT (340/84) and the Fondo de Investigaciones Sanitarias de la Seguridad Social.

\section{REFERENCES}

Barnard, E. A. (1975). Hexokinases from yeast. Methods in Enzymology 42C, 6-20.

Blowers, D. P. \& Trewavas, A. J. (1987). Autophosphorylation of plasma membrane bound calcium calmodulin dependent protein kinase from pea seedlings and modification of catalytic activity by autophosphorylation. Biochemical and Biophysical Research Communications 143, 691-696.

Britton, P., Murfitt, D., Parra, F., Jones-Mor-
TIMER, M. C. \& KornBerg, H. L. (1982). Phosphotransferase-mediated regulation of carbohydrate utilisation in Escherichia coli K12: identification of the products of genes on the specialised transducing phages $\lambda$ iex (crr) and גgsr (tgs). EMBO Journal 1, 907-911.

Colowick, S. P. (1973). The hexokinases. In The Enzymes, 3rd edn, vol. 9, pp. 1-48. Edited by P. D. Boyer. New York: Academic Press. 
Entian, K. D. \& Mecke, D. (1982). Genetic evidence for a role of hexokinase isozyme PII in carbon catabolite repression in Saccharomyces cerevisiae. Journal of Biological Chemistry 257, 870-874.

Entian, K. D., Kopetzki, E., Frohlich, K. U. \& MECKE, D. (1984). Cloning of hexokinase isoenzyme PI from Saccharomyces cerevisiae: PI transformants confirm the unique role of hexokinase isoenzyme PII for glucose repression in yeasts. Molecular and General Genetics 198, 50-54.

Entian, K. D., Hilberg, F., Opitz, H. \& Mecke, D. (1985). Cloning of hexokinase structural genes from Saccharomyces cerevisiae mutants with regulatory mutations responsible for glucose repression. Molecular and Cellular Biology 5, 3035-3040.

Erlichman, J., Rangel-Aldao, R. \& Rosen, O. M. (1983). Reversible autophosphorylation of type II cAMP-dependent protein kinase: distinction between intramolecular and intermolecular reactions. Methods in Enzymology 99, 176-186.

Fernández, R., Herrero, P., Gascon, S. \& Moreno, F. (1984). Xylose induced decrease in hexokinase PII activity confers resistance to carbon catabolite repression of invertase in Saccharomyces carlsbergensis. Archives of Microbiology 139, 139-142.

Fernández, R., Herrero, P., Fernández, M. T. \& MORENO, F. (1986). Mechanism of inactivation of hexokinase PII of Saccharomyces cerevisiae by Dxylose. Journal of General Microbiology 132, 34673472.

Fernández, T., Herrero, P., Lopez-BoAdo, Y. S.,
Fernández, R. \& Moreno, F. (1987). Proteolysis of hexokinase PII is not the triggering signal of carbon catabolite derepression in Saccharomyces cerevisiae. Journal of General Microbiology 133, 2509-2516.

Frohlich, K. U., EnTIAN, K. D. \& MECKE, D. (1984). Cloning and restriction analysis of the hexokinase PII gene of the yeast Saccharomyces cerevisiae. Molecular and General Genetics 194, 144-148.

Huang, K. P., Chan, K. F. J., Singh, T. J., Nakabayashi, H. \& Huang, F. L. (1986). Autophosphorylation of rat brain $\mathrm{Ca}^{2+}$-activated and phospholipid-dependent protein kinase. Journal of Biological Chemistry 261, 12134-12140.

LaI, Y., NaIRN, A. C. \& Greengard, P. (1986). Autophosphorylation reversibly regulates the $\mathrm{Ca}^{2+}$ calmodulin-dependence of $\mathrm{Ca}^{2+} /$ calmodulindependent protein kinase II. Proceedings of the National Academy of Sciences of the United States of America 83, 4253-4257.

Moreno, F., Fernández, M. T., Fernández, R. \& HerRero, P. (1986). Hexokinase PII from Saccharomyces cerevisiae is regulated by changes in the cytosolic $\mathrm{Mg}^{2+}$-free ATP concentration. European Journal of Biochemistry 161, 565-569.

Rodicio, R. \& ZimmERMANN, F. K. (1985). Cloning of maltase regulatory genes in Saccharomyces cerevisiae. Current Genetics 9, 539-545.

ShiA, M. A., Rubin, J. B. \& Pilch, P. F. (1983). The insulin receptor protein kinase physicochemical requirements for activity. Journal of Biological Chemistry 258, 14450-14455. 